\title{
Analysis of Frame Structure under Uneven Settlement and Earthquake
}

\author{
Peng Deng ${ }^{* 1, a}$, Fei Qin ${ }^{2, b}$, Huiling Wang ${ }^{3, c}$ \\ ${ }^{1}$ Shandong Provincal Key Laboratory of Civil Engineering Disaster Prevention and Mitigation, \\ Shandong University of Science and Technology, Qingdao, Shandong, 266590, China \\ ${ }^{2}$ College of Civil Engineering and Architecture, Shandong University of Science and \\ Technology,Qingdao, Shandong 266590, China \\ adengpeng1226@163.com, b510883471@qq.com , cdrawingfish@qq.com
}

Keywords: uneven settlement, frame structure, seismic action, time-history analysis

Abstract. The coal mining and the development of urban underground space have leaded to the differential settlement of the building and its damage to buildings should not be ignored. In this paper, the frame structure finite element model is made by ANSYS which considers two conditions including settlement range extension and settlement amount increase. The horizontal displacement and plastic development rules of the frame structure under uneven settlement and rare earthquake have been studied through its dynamic time-history analysis.

\section{Introduction}

The coal mining and the development of urban underground space have leaded to the differential settlement of the building whose damage to buildings should not be ignored [1]. It is significant to solve the contradiction between underground mining and ground buildings protection by studying the effect of uneven settlement and the earthquake on the deformation and force of buildings [2-5]. As the shortage of force simulation and experiment research of frame structure under the surface uneven settlement and seismic action, it is significant to study the force, displacement change rule, the weak part and plastic development of the structure, which has reference value to the practical engineering.

\section{The establishment of the finite element model}

The finite element model established in this paper is a six- layer concrete frame structure that uses independent foundations, and the plan of the first floor is shown in figure 1.The height of the first floor is $3.3 \mathrm{~m}$, and other floors are $3 \mathrm{~m}$. The site classification is class II , and the seismic fortification intensity is 8 degrees. The section of frame beams and columns is $250 \mathrm{~mm} \times 500 \mathrm{~mm}$ and $600 \mathrm{~mm} \mathrm{x}$ $600 \mathrm{~mm}$ respectively, and the thickness of floor slab is $120 \mathrm{~mm}$. The concrete is C30. The elastic modulus is $3 \times 10^{4} \mathrm{~N} / \mathrm{mm}^{2}$, and Poisson's ratio is 0.2 . The assumption is used in the paper that reinforced concrete is ideal elastic plastic material. The floor live load is $3 \mathrm{kN} / \mathrm{m}^{2}$, and roof live load is $0.5 \mathrm{kN} / \mathrm{m}^{2}$. The finite element model of the frame is shown in figure 2.

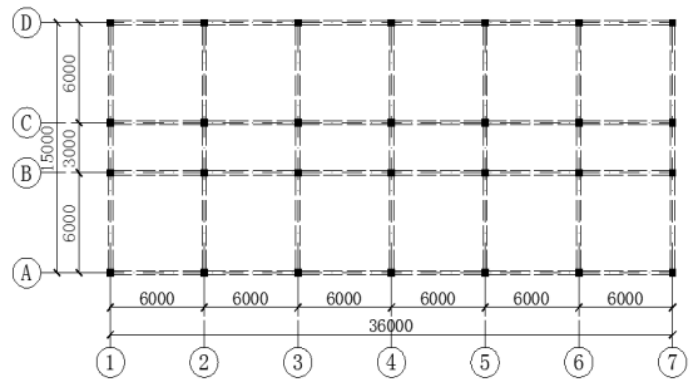

Fig.1 Floor plan

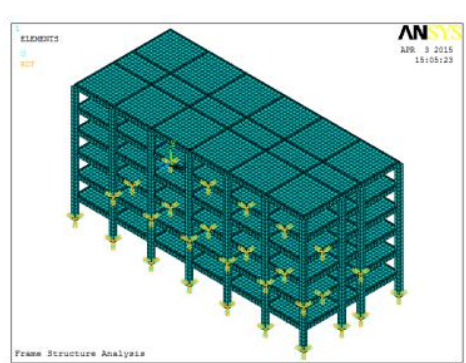

Fig.2 Finite element model of structure

To simplify the analysis process, the framework structure is located in the center of subsidence basin and the influence of uneven settlement on frame structure has been simulated by applying vertical symmetrical displacement to the frame from center to two sides. The displacements of working conditions under settle range extension and settle increase are shown in table 1 and table 2. 


\section{The force analysis of frame structure under uneven settlement and seismic force}

The model adopts EL CENTRO seismic wave only in the longitudinal direction of the structure. Through the analysis of elastic time history and the elastic-plastic time history at 8 degree earthquake during frequent earthquake and rare earthquake respectively, the dynamic response of a frame structure under dual function and the elastic-plastic developments can be studied.

Table 1 Surface subsidence of different range (unit: $\mathrm{mm}$ )

\begin{tabular}{c|c|c|c|c}
\hline \multirow{2}{*}{ condition } & \multicolumn{4}{|c}{ subsidence values } \\
\cline { 2 - 5 } & (1)、(7)column & (2)、 6)column & (3)、(5)column & (4)column \\
\hline S1 & 0 & 0 & 0 & 0 \\
\hline S2 & 0 & 0 & 0 & 12 \\
\hline S3 & 0 & 0 & 12 & 24 \\
\hline S4 & 0 & 12 & 24 & 36 \\
\hline
\end{tabular}

Table 2 Surface subsidence of different settlement (unit: $\mathrm{mm}$ )

\begin{tabular}{c|c|c|c|c}
\hline \multirow{2}{*}{ condition } & \multicolumn{4}{|c}{ subsidence values } \\
\cline { 2 - 5 } & (1)、(7)axis & (2) (6)axis & (3)、(5)axis & (4)axis \\
\hline S1 & 0 & 0 & 0 & 0 \\
\hline S4 & 0 & 12 & 24 & 36 \\
\hline S5 & 0 & 18 & 36 & 54 \\
\hline S6 & 0 & 24 & 48 & 72 \\
\hline S7 & 0 & 30 & 30 & 90 \\
\hline
\end{tabular}

Elastic time history analysis of uneven settlement structure under frequent and rare earthquake. The time histories of top displacement under the conditions of the settlement range extension under frequent earthquake are shown in figure 3. And the settlement range extension has no obvious influence on the top displacement of the structure. The top displacements under the conditions of the settlement range extension under rare earthquake are shown in figure4.

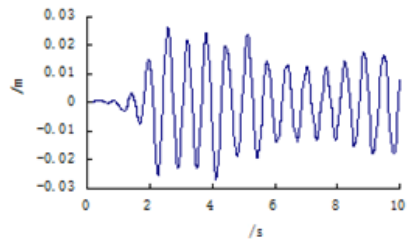

(a)condition 1

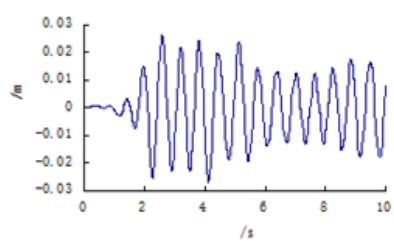

(b)condition 2

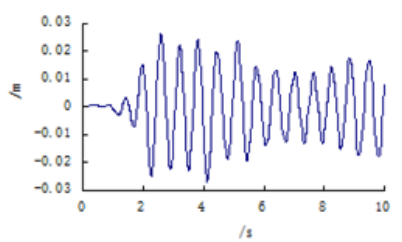

(c)condition 3

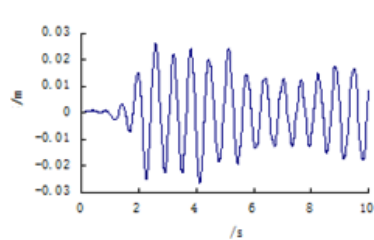

(d)condition 4

Fig.3 Displacement versus time date curve of a top point

With the development of the uneven settlement from the center to the two sides, the time history curves of top displacement of structure are coincident within 0 to 2 seconds, and there is an obvious difference at the wave crest within 2 to10 seconds.Compared with no settlement in S1, the maximum top displacement in $\mathrm{S} 2 \sim \mathrm{S} 4$ reduced $2.54 \%, 4.59 \%$ and $6.71 \%$ respectively.

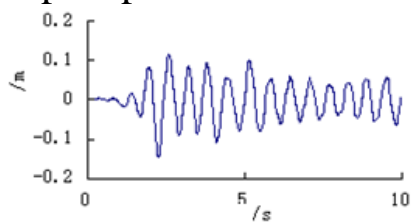

(a)condition 1

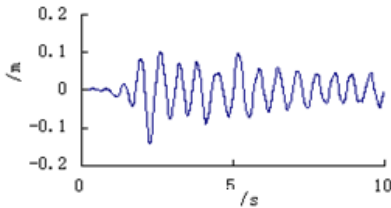

(b)condition 2

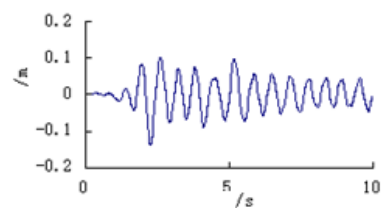

(c)condition 3

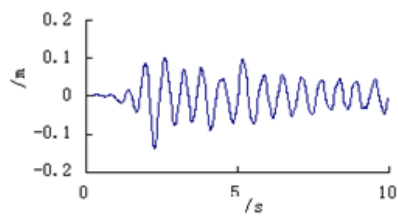

(d)condition 4

Fig.4 Displacement versus time curve of a top point

The maximum horizontal displacement and the change law of the layer displacement under all conditions of settlement increase under rare earthquake are shown in figure 5 and 6 , which is similar to the law of displacement under conditions of settlement range extension. The maximum horizontal 
displacement and interlayer displacement of frame structure gradually decrease and the reduce amplitude also decreases gradually with settlement increase from Figure 5 and 6. The change of settlement has significant effect on the interlayer displacement in the middle, but a little effect on top and first floor. From above analysis, the conclusion can be got that the displacement between layers reduces as settlement increases. The inter-story displacement angle under settlement change meets the Seismic design code that elastic-plastic inter-story displacement angle of reinforced concrete structure limits to $1 / 50$.

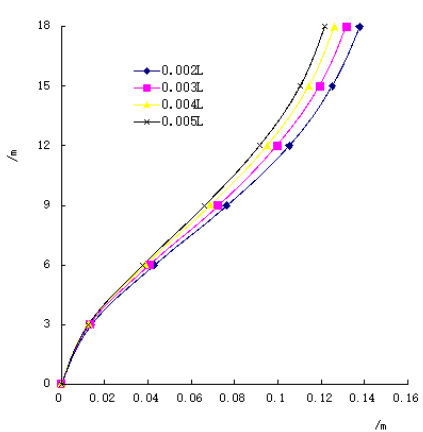

Fig.5 Maximum story displacement on different settlements

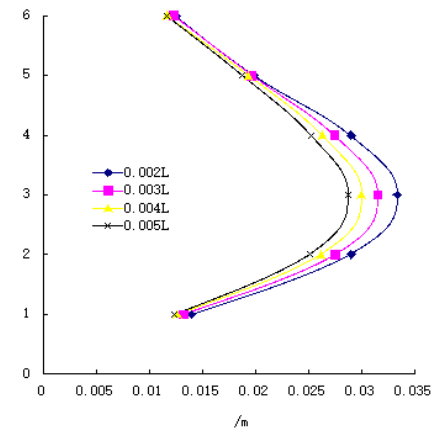

Fig.6 Maximum inter-story displacement on different settlements

Elastic-plastic time history analysis of uneven settlement structure under rare earthquake. In order to study the plastic deformation of the structure during the whole process of the earthquake, $10 \mathrm{~s}$ of EL Centro wave was used in ANSYS under rare earthquake at 8 degree. In this paper, the plasticity at the key time points has been studied.

The plastic strains at key points under condition 1 are shown in figure 7 and 8 . The beam ends on the first and second layers reached plasticity firstly at $2.18 \mathrm{~s}$ and those from the first floor to the third floor reached plasticity at $2.46 \mathrm{~s}$ under left earthquake.

The plastic strains at key points under condition 2 are shown in figure 9 and 10 . The beam ends on the first and second layers reached plasticity firstly at 1.88s. The beams of adjacent spans at axis 4 that reached plasticity were up to the fourth floor while plastic deformation occurred on beams of other spans only at the first and second floor at maximum point $2.14 \mathrm{~s}$ under right earthquake. The beams of adjacent spans at axis 4 that reached plasticity were up to the fifth floor while beams of other spans were only up to the fourth floor at maximum point 2.46 s under left earthquake.

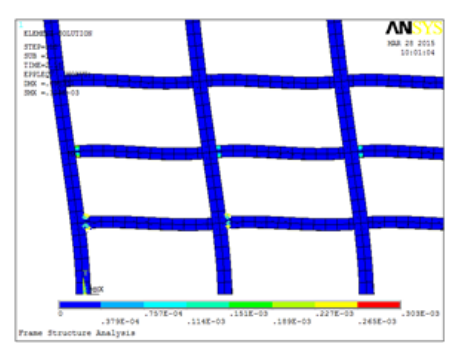

Fig.7 Plastic strain chart at $2.18 \mathrm{~s}$

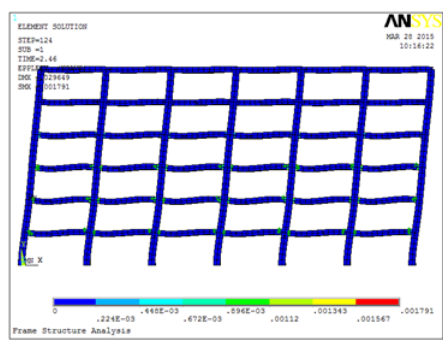

Fig.8 Plastic strain chart at $2.46 \mathrm{~s}$

The plastic strains at key points under condition 2 are shown in figure 9 and 10 . The beam ends on the first and second layers reached plasticity firstly at 1.88s. The beams of adjacent spans at axis 4 that reached plasticity were up to the fourth floor while plastic deformation occurred on beams of other spans only at the first and second floor at maximum point $2.14 \mathrm{~s}$ under right earthquake. The beams of adjacent spans at axis 4 that reached plasticity were up to the fifth floor while beams of other spans were only up to the fourth floor at maximum point 2.46s under left earthquake.

The plastic strains at key points under condition 3 are shown in figure 11 and 12 . And the elasticity development laws of the structure are similar to those under condition 2. 
The plastic strains at key points under condition 4 are shown in figure 13 and 14. The beam ends from the first to the third floor reached plasticity firstly at 1.88s. And the development laws of beams of other spans are similar to those under condition 2.

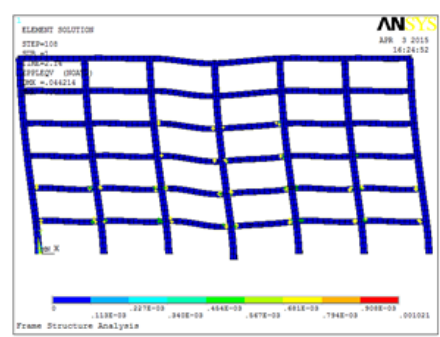

Fig.9 Plastic strain charts at $2.14 \mathrm{~s}$
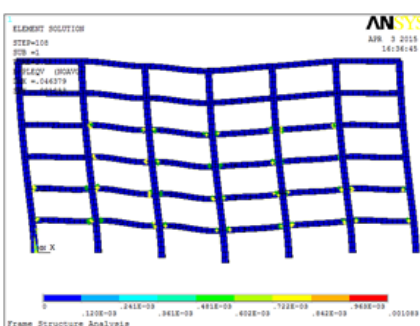

Fig.11 Plastic strain charts at 2.14s

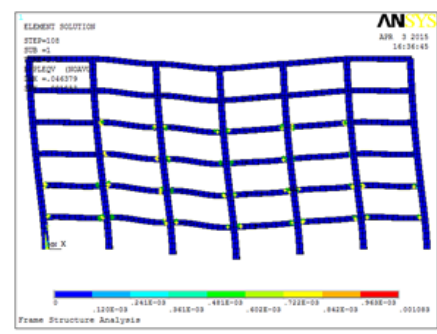

Fig.13 Plastic strain at 2.14s

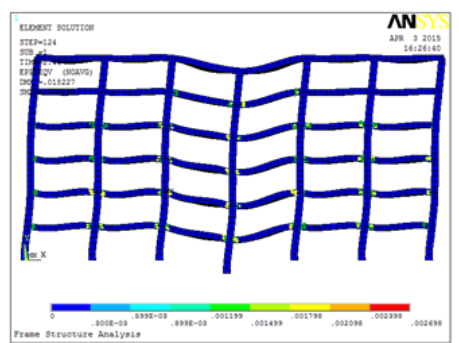

Fig.10 Plastic strain charts at $2.46 \mathrm{~s}$

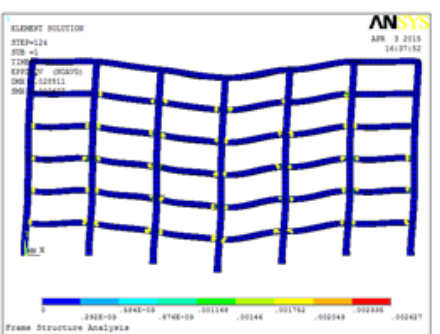

Fig.12 Plastic strain charts at 2.46s

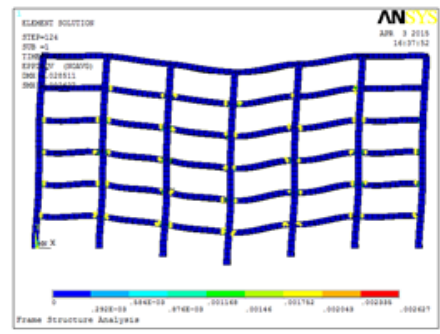

Fig.14 Plastic strain at 2.46s

\section{Conclusion}

The influence of different working conditions on nature period of frame can be ignored when relative settlement between columns is within the scope of the specification allows. In the case of frequent earthquake, the seismic response of the structure under different settlement is similar to that of no settlement. In the case of rare earthquake, the plastic behavior of structure under settlement appears earlier than that of no settlement. When the settlement range expands with the same relative settlement between pillars, the plastic development laws of structure are similar that plasticity of beam ends at the first floor appears firstly and scales up gradually within the settlement range.

\section{References}

[1] Qihu Qian. Current situation and Prospect of development and utilization of urban underground space in China [J]. air defense of Chinese people 2007;S1(5):5-12, in Chinese

[2] Song Xu, Changhong Yan, Yazhe Sun. Environmental geotechnical engineering problems in urban underground engineering [J].engineering geology 2003;11(2):127-132, in Chinese

[3] Guangming Yu, Heping Xie.Numerical Simulation of Fractal Interface Effect of Mining-Caused Activation of Fault [J]. Discrete Dynamics in Nature and Society 2002; 7(3):151-155

[4] L. Kellezi. Local transmitting boundaries for transient elastic analysis[J].Soil dynamics and earthquake engineering 2000;9(7):533-547

[5] Chang Liu, Gang Zheng. Analysis of the influence of ground unequal settlement on the structure with elastic support model method[J]. Journal of Building Structures 2004;25(4):124-128, in Chinese 